\title{
Mesospheric gravity waves observed near equatorial and low-middle latitude stations: wave characteristics and reverse ray tracing results
}

\author{
C. M. Wrasse ${ }^{1}$, T. Nakamura ${ }^{2}$, H. Takahashi ${ }^{1}$, A. F. Medeiros ${ }^{3}$, M. J. Taylor ${ }^{4}$, D. Gobbi ${ }^{1}$, C. M. Denardini ${ }^{1}$,

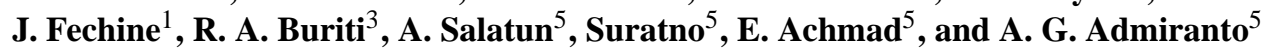 \\ ${ }^{1}$ Instituto Nacional de Pesquisas Espaciais (INPE), C.P. 515, 12245-970, São José dos Campos, Brazil \\ ${ }^{2}$ Institute for Sustainable Humanosphere (RISH), Kyoto University, Uji, Kyoto, 611-0011, Japan \\ ${ }^{3}$ Universidade Federal de Campina Grande (UFCG), Av. Aprígio Veloso 882, Bodocongó, 58109-970, Campina Grande, \\ Brazil \\ ${ }^{4}$ Space Dynamics Laboratory and Physics Department, Logan, UT 84322-4145, USA \\ ${ }^{5}$ Space Science Center, National Institute of Aeronautics and Space, Jalan Pemuda Persil 1, Rawamangun, 13220, Jakarta, \\ Indonesia
}

Received: 20 June 2006 - Revised: 17 November 2006 - Accepted: 27 November 2006 - Published: 21 December 2006

\begin{abstract}
Gravity wave signatures were extracted from $\mathrm{OH}$ airglow observations using all-sky CCD imagers at four different stations: Cachoeira Paulista $(\mathrm{CP})\left(22.7^{\circ} \mathrm{S}, 45^{\circ} \mathrm{W}\right)$ and São João do Cariri $\left(7.4^{\circ} \mathrm{S}, 36.5^{\circ} \mathrm{W}\right)$, Brazil; Tanjungsari (TJS) $\left(6.9^{\circ} \mathrm{S}, 107.9^{\circ} \mathrm{E}\right)$, Indonesia and Shigaraki $\left(34.9^{\circ} \mathrm{N}\right.$, $\left.136^{\circ} \mathrm{E}\right)$, Japan. The gravity wave parameters are used as an input in a reverse ray tracing model to study the gravity wave vertical propagation trajectory and to estimate the wave source region. Gravity waves observed near the equator showed a shorter period and a larger phase velocity than those waves observed at low-middle latitudes. The waves ray traced down into the troposphere showed the largest horizontal wavelength and phase speed. The ray tracing results also showed that at CP, Cariri and Shigaraki the majority of the ray paths stopped in the mesosphere due to the condition of $m^{2}<0$, while at TJS most of the waves are traced back into the troposphere. In summer time, most of the back traced waves have their final position stopped in the mesosphere due to $m^{2}<0$ or critical level interactions $(|m| \rightarrow \infty)$, which suggests the presence of ducting waves and/or waves generated in-situ. In the troposphere, the possible gravity wave sources are related to meteorological front activities and cloud convections at $\mathrm{CP}$, while at Cariri and TJS tropical cloud convections near the equator are the most probable gravity wave sources. The tropospheric jet stream and the orography are thought to be the major responsible sources for the waves observed at Shigaraki.
\end{abstract}

Keywords. Meteorology and atmospheric dynamics (Middle atmosphere dynamics; Waves and tides; Instruments and techniques)

Correspondence to: C. M. Wrasse

(cristiano.wrasse@yahoo.com.br)

\section{Introduction}

Atmospheric gravity waves (AGW) are a very important factor for studies in the dynamical regime of the middle and upper atmosphere. As the gravity waves propagate through the upper mesosphere and lower thermosphere (MLT) regions, the perturbations of the local density and temperature affect the photochemical balance of the surrounding resulting wavelike modulations in the airglow emission rates (Schubert and Waterscheid, 1988; Tarasick and Hines, 1990; Swenson and Gardner, 1998). Gravity waves in the MLT region, then, can be observed by using CCD airglow imagers and the wave parameters, such as horizontal wavelength and phase velocity, can be obtained from them (e.g. Hecht et al., 1994; Taylor et al., 1995, 1997; Nakamura et al., 1999; Swenson et al., 1999; Medeiros et al., 2001). This technique provides a simple and useful method to investigate the horizontal characteristics of the atmospheric gravity waves and their temporal evolution.

Recent progress on the theoretical, numerical and observational studies of gravity waves was reviewed by Fritts and Alexander (2003). They also pointed out that ray tracing is one of the useful techniques to investigate gravity wave propagation through the atmosphere (e.g. Ekermann and Marks, 1997; Brown et al., 2004; Gerrard et al., 2004). The reverse mode of ray tracing has also been used to locate the source of the gravity wave disturbances (Bertin et al., 1978; Hertzog et al., 2001; Wrasse et al., 2003, 2006). This technique is useful to estimate the source region in the lower heights from the gravity wave signatures observed in the upper mesosphere and lower thermosphere region.

Observational studies of the gravity wave characteristics and seasonal variations of the propagation direction have

Published by Copernicus GmbH on behalf of the European Geosciences Union. 


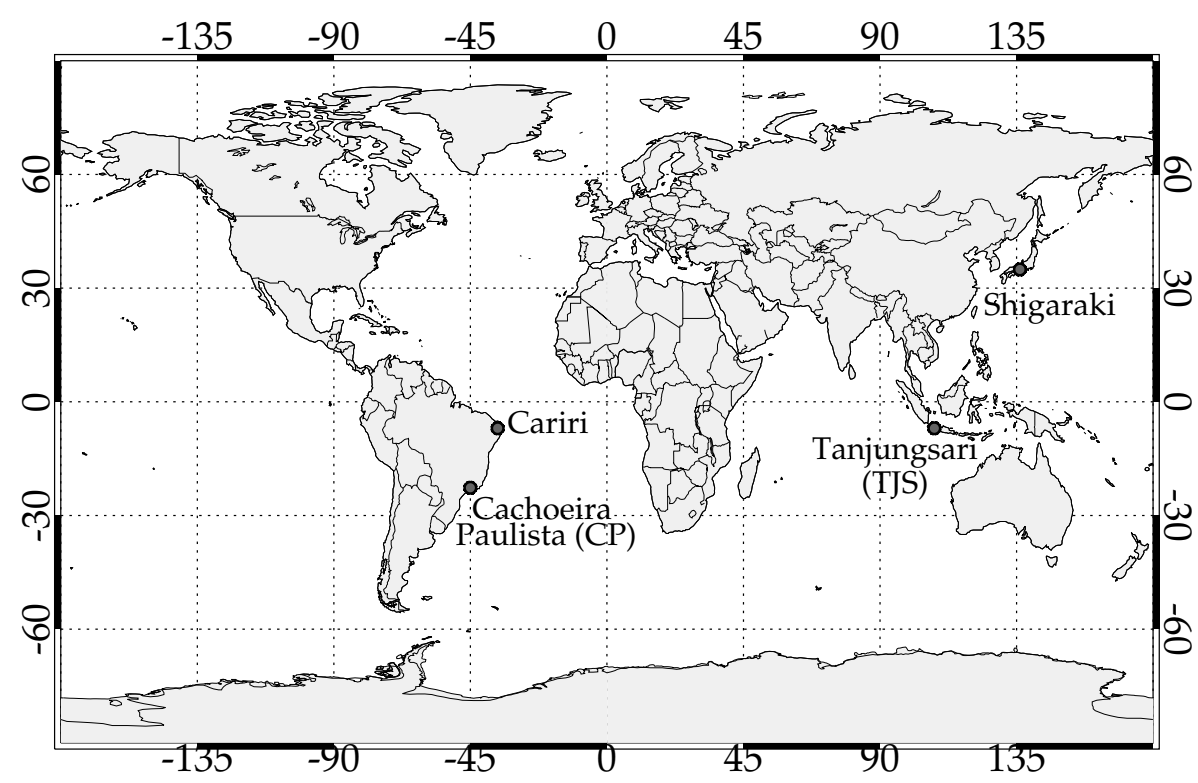

Fig. 1. World map showing the location of the four observation sites used to investigate the gravity waves observed in the $\mathrm{OH}$ airglow emission.

been performed by many researchers from several locations (e.g. Walterscheid et al., 1999; Nakamura et al., 1999, 2003; Hecht et al., 2001; Medeiros et al., 2004). However, little has been discussed in the gravity wave source locations. In the present paper, gravity waves observed by $\mathrm{OH}$ airglow imaging at four different ground-based stations are used to investigate the wave characteristics, propagation direction, and localize the possible wave source region using a reverse ray tracing method.

\section{Observations}

Gravity wave observations using an all-sky airglow $\mathrm{OH}$ imager were carried out at four different stations, Cachoeira Paulista $\left(22.7^{\circ} \mathrm{S}, 45^{\circ} \mathrm{W}\right)$, hereafter CP, São João do Cariri $\left(7.4^{\circ} \mathrm{S}, 36.5^{\circ} \mathrm{W}\right)$, hereafter Cariri, both in Brazil; Tanjungsari $\left(6.9^{\circ} \mathrm{S}, 107.9^{\circ} \mathrm{E}\right)$, hereafter TJS, Indonesia, and Shigaraki $\left(34.9^{\circ} \mathrm{N}, 136^{\circ} \mathrm{E}\right)$, Japan. Figure 1 shows the map locations of the four observatories.

The observations at $\mathrm{CP}$ were taken using an all-sky CCD imager, with a $180^{\circ}$ field of view, to monitor the spatial and temporal variations of the $\mathrm{OH}$ airglow layer. The measurements were made from October 1998 to September 1999, and 143 gravity wave events were observed. Horizontal wavelengths of the gravity waves are determined by applying a standard 2-D FFT analysis in the observed airglow images. The advantage of this method is that it is possible to process all of the monochromatic waves present in the images individually. We can localize the gravity wave content in any part of the image by isolating the region of interest, taking its 2-D FFT and identifying peaks in the frequency spectrum
(Medeiros et al., 2004). Only the main peak in the spectrum is used. The period and the phase speed of the gravity wave are determined by applying a 1-D FFT in time to the complex 2-D FFT in space. The peak in the 1-D FFT corresponds to the wave frequency. Details of the equipment, data acquisition and methodology to determine the wave parameters have been reported by Medeiros et al. (2001).

Airglow observations were also carried out at Cariri, where another all-sky CCD imager has been operated. The imager has similar characteristics to that operated at CP. The observations were taken from September 2000 to October 2001 and a total of 326 gravity waves were observed. Medeiros et al. (2004) reported the details of the imager system, data analysis, as well as the determination of gravity wave parameters using the same methodology for $\mathrm{CP}$ and Cariri.

At TJS, a simple wide view CCD imager has also been operated and measuring the $\mathrm{OH}$ airglow emissions since 2000. The camera has a field of view of $128^{\circ}$ in the diagonal direction, and $89^{\circ}$ and $88^{\circ}$ in the north-south and east-west directions, respectively. For the present study the image data taken from September 2000 to September 2001 were used, giving a total of 238 nights of observations, of which 74 gravity waves were extracted. Image data were first translated into geographical coordinates, and then differential images between two adjacent exposures were calculated in order to enhance the gravity waves seen in the airglow image (Swenson and Mende, 1994). Dominant gravity waves were extracted and the main wave parameters were determined if the wave was seen on at least two sequential differential images. Nakamura et al. (2003) reported the details of the 
instrument characteristics, data analysis and the determination of the gravity wave parameters for the data taken at TJS.

Prior to the TJS image observations, the same wide view CCD imager was operated at Shigaraki, Japan, between November 1996 and May 1998. A total of 161 nights with observations and 534 gravity waves were detected in the $\mathrm{OH}$ images. The horizontal wavelength and the propagation direction of the gravity waves are determined from the images in the geographic coordinate by applying a 2-D FFT. The horizontal phase speed can be derived from several successive images, and then the observed wave period is calculated. Nakamura et al. (1999) has reported the data analysis and the determination of the gravity wave parameters, as well as the climatology of the gravity waves observed at Shigaraki.

It should be noted that due to the instrumental limitation it is not possible to observe waves with horizontal wavelengths larger than the field of view, which is about $800 \mathrm{~km}$ at the $90 \mathrm{~km}$ altitude, for the imager at $\mathrm{CP}$ and Cariri, while at TJS and Shigaraki it is around $200 \mathrm{~km}$. Also difficult to observe are waves with vertical wavelengths shorter than $10 \mathrm{~km}$ (thickness of the emission layer). In practice, further observable horizontal wavelengths may be much less than the imager field of view because of image distortion as the zenith angle increases. The shortest period of gravity waves is limited by the Brunt Väisälä frequency, i.e. around $5 \mathrm{~min}$ at the altitude of $\mathrm{OH}$ airglow layer $(\sim 87 \mathrm{~km})$.

\section{Gravity wave ray tracing model}

A reverse ray tracing model is used to compute the back trajectory of the observed gravity waves in order to estimate its source region. The ray tracing technique has been widely used in the gravity wave study and the basic ray tracing equations have been described by Lighthill (1978) and Jones (1969). In the present study we employed the ray tracing model used in Wrasse et al. (2006), which followed the previous work of Marks and Eckermann (1995). We did not consider any damping mechanisms and did not track the wave action density through the wave trajectory, mainly due to the lack of amplitude information in our data set. For each measured wave event the observed horizontal wavelength, propagation direction, phase speed, period and local time are the launch parameters of one ray. In addition, it is also necessary to know the background atmospheric wind and temperature. Since we have no simultaneous observation of the vertical wind profile, in the present study climatological models, CIRA-1986 zonal wind and temperature (Fleming et al., 1990), and GSWM-02 tidal wind parameters (Hagan and Forbes, 2003), are used to create the background wind and temperature conditions. The GSWM-02 model varies horizontally and vertically, as well as temporally, while the CIRA-86 model does not include temporal variation. This information is needed as a function of height within an area of \pm 15 degrees in latitude and longitude around each ob- servation site. As the CIRA-86 model does not provide a meridional wind component, the meridional wind consists only of the tidal wind from the GSWM-02. To ensure that the WKB approximation remains valid for the ray parameters, the numerical integration was stopped under any of the following conditions: 1) $\mathrm{m}^{2}$ becomes negative, i.e. the wave cannot propagate vertically; 2) $\mathrm{m}^{2}$ becomes larger than $1 \times 10^{-6}\left(\mathrm{cyc}^{2} / \mathrm{m}^{2}\right)$, i.e. vertical wavelength becomes smaller than $1 \mathrm{~km}$ and it is close to a critical level; 3) the intrinsic frequency $\hat{\omega} \rightarrow 0$ or $\hat{\omega}<0$, i.e. $|m| \rightarrow \infty$ which means that the wave is approaching to a critical level and the wave packet is likely to break. The position where the ray tracing is stopped due to one of the previous conditions will be referred hereafter as the "final position" of the wave.

Wrasse et al. (2006) discussed the limitation of the reverse ray tracing method and estimated the error range, taking into account the effects of the background wind variation caused by the tidal variability. They found that for $75 \%$ of the cases, the error range fell into a region with a radius less than $200 \mathrm{~km}$, and in a few exceptional cases, the ray tracing path stopped in the mesosphere, showing the sensitivity with respect to the wind variation.

\section{Results}

\subsection{Gravity wave characteristics}

The observed gravity waves parameters, horizontal wavelength, period and horizontal phase speed are presented in Fig. 2 for all four stations. Figure 2a shows the gravity wave characteristics observed at $\mathrm{CP}\left(23^{\circ} \mathrm{S}\right)$, where the horizontal wavelength is distributed mainly between 10 and $30 \mathrm{~km}$, the period ranging from 5 to $15 \mathrm{~min}$ and typical phase speed between 10 and $40 \mathrm{~m} / \mathrm{s}$. At Cariri $\left(7^{\circ} \mathrm{S}\right)$, in Fig. $2 \mathrm{~b}$, the horizontal wavelength ranges mainly between 5 and $25 \mathrm{~km}$, and the observed period varies principally between 5 and $10 \mathrm{~min}$. The horizontal phase speed varies from 10 to $65 \mathrm{~m} / \mathrm{s}$. At TJS $\left(7^{\circ} \mathrm{S}\right)$, Fig. $2 \mathrm{c}$, the horizontal wavelength is mainly distributed between 5 and $30 \mathrm{~km}$, the typical observed period is ranging from 5 to $10 \mathrm{~min}$ and the phase speed varies between 25 to $75 \mathrm{~m} / \mathrm{s}$. At Shigaraki $\left(35^{\circ} \mathrm{N}\right)$, Fig. $2 \mathrm{~d}$, the observed gravity waves showed a horizontal wavelength ranging mainly between 5 and $40 \mathrm{~km}$. The observed period has a maximum occurrence between 5 and $15 \mathrm{~min}$, whereas the phase speed ranges from 10 to $70 \mathrm{~m} / \mathrm{s}$.

Two airglow imagers used at the Brazilian sites are similar, which makes the comparison of the gravity wave parameters between CP and Cariri easier and reasonable. The same comparison can be done for the image data at TJS and Shigaraki with the same reason. The horizontal wavelengths observed at $\mathrm{CP}$ and Cariri are similar, showing a maximum occurrence between 5 and $25 \mathrm{~km}$; however, the observed periods at $\mathrm{CP}$ are longer than at Cariri. It should be noted that at Cariri the phase velocity is faster than at CP. Gravity waves observed at 

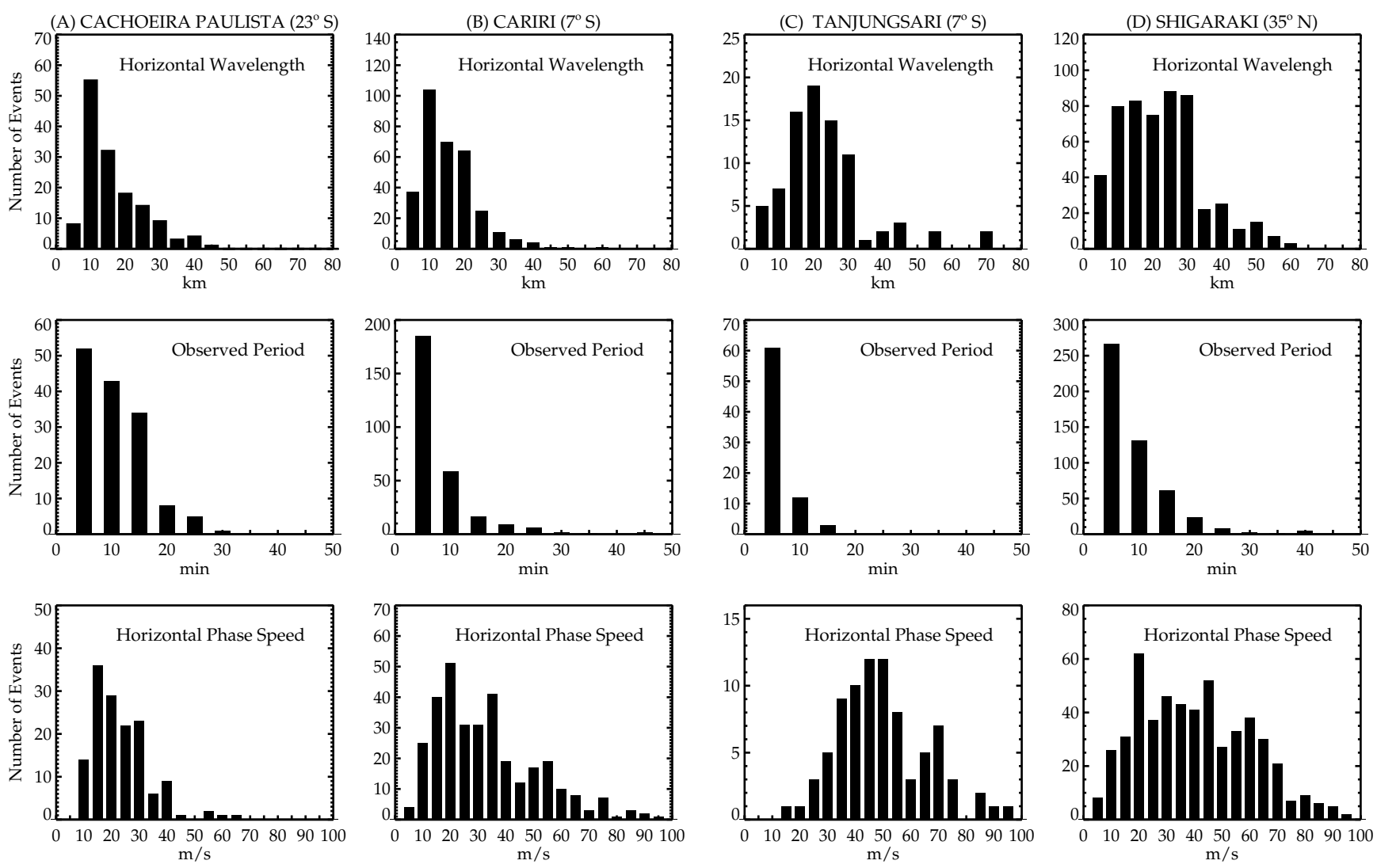

Fig. 2. Histogram plots showing the distribution of gravity waves parameters at (A) Cachoeira Paulista, (B) Cariri, (C) Tanjungsari and (D) Shigaraki. The panels show, from top to bottom, the horizontal wavelength, observed period and horizontal phase speed.

Shigaraki and at TJS showed horizontal wavelength ranging mostly between 5 and $30 \mathrm{~km}$. The observed period is larger at Shigaraki than at TJS. On the other hand, the phase speed at TJS showed a maximum occurrence between 25 and $75 \mathrm{~m} / \mathrm{s}$, while at Shigaraki the phase speeds are distributed mostly between 10 and $70 \mathrm{~m} / \mathrm{s}$. It should be noted that the gravity waves observed near the equator have a shorter period and larger phase velocity compared to those waves observed at low-middle latitudes.

The difference between the gravity wave parameters observed at CP, Cariri, TJS and Shigaraki could not be attributed to the difference between the equipment. The errors of the observed wave parameters are much smaller than the instrumental limitations of the imagers. It is most probable that the observed differences are due to the difference in geographic latitude between the four sites, where the background wind velocities are different.

Figure 3 presents the histogram of the seasonal variation of the gravity wave propagation direction. The observation is divided into four periods corresponding to spring (September-October), summer (November-February), autumn (March-April) and winter (May-August) for the Southern Hemisphere. For the Northern Hemisphere, namely
Shigaraki, the period is divided in spring (March-April), summer (May-August), autumn (September-October) winter (November-February).

Figure 3a shows plots of the propagation direction for the gravity waves observed at $\mathrm{CP}$. The wave propagation directions during the summer (November-February) and winter (May-August) are mainly eastward and westward, respectively. In the spring (September-October) most of the waves propagate in the northeastward direction. During the autumn (March-April) the wave propagation is divided into two preferential directions: northwestward and northeastward.

Figure $3 \mathrm{~b}$ presents the propagation direction of the gravity waves observed at Cariri. The propagation is typically eastward during the spring (September-October). In the summer (November-February) the preferential propagation is distributed in the northeastward and southeastward directions. During the autumn (March-April), the waves propagate preferentially northward and southward. In winter (May-August) the waves showed a northward propagation direction. It is noteworthy that the eastward propagation is preferable for all the seasons at Cariri.

Figure 3c shows the gravity wave propagation directions at TJS. During the Southern Hemisphere's spring 

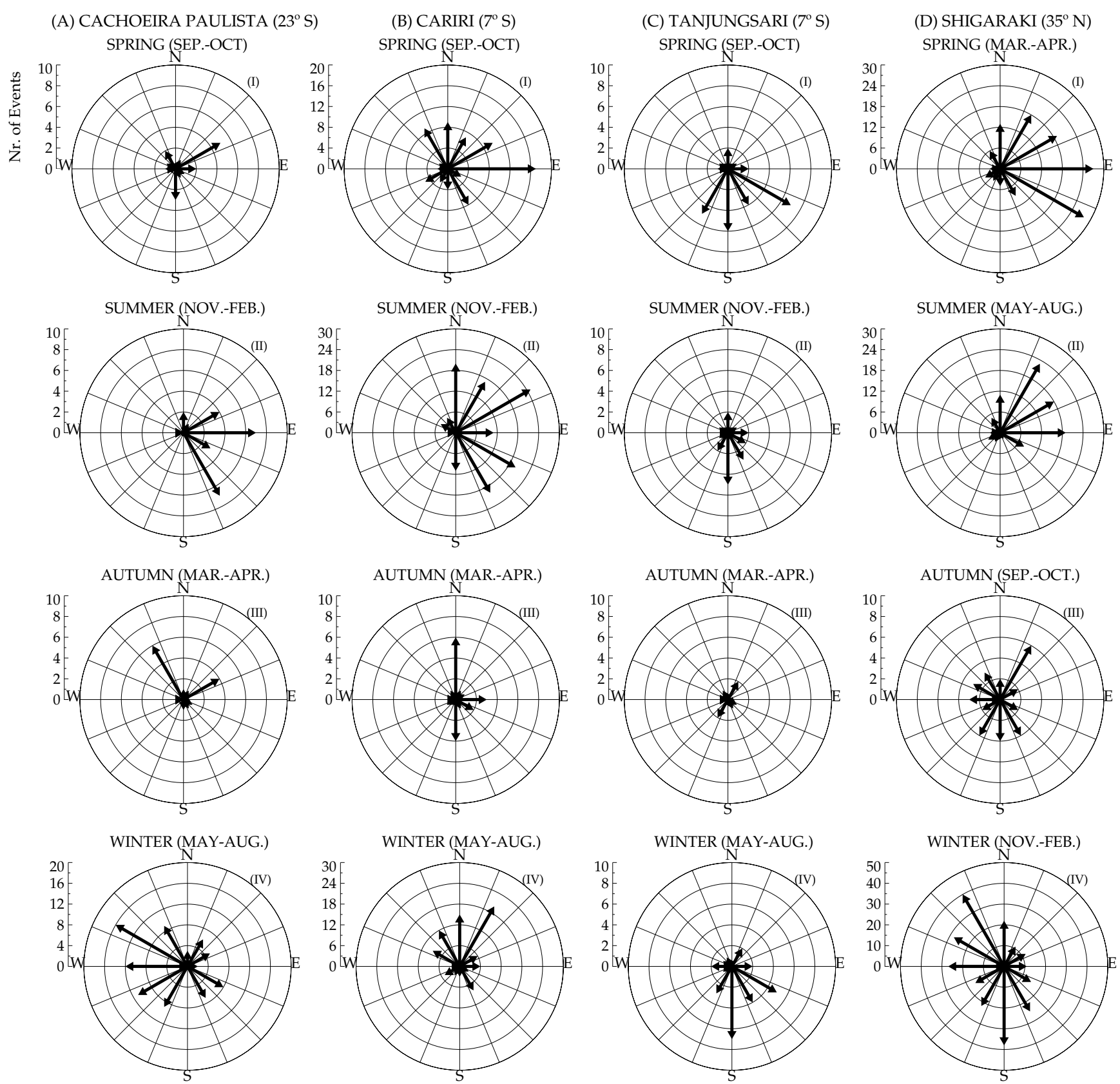

Fig. 3. Azimuthal plots showing the histogram of the seasonal variation for gravity wave propagation directions observed at (A) Cachoeira Paulista, (B) Cariri, (C) Tanjungsari and (D) Shigaraki. The rows show, from top to bottom, data for spring, summer, autumn and winter in Southern and Northern hemispheres. In each season the corresponding months are indicated in parenthesis.

(September-October), summer (November-February) and winter (May-August), the waves propagate preferentially to the south. In the autumn (March-April), however, no preferential propagation direction is observed.

The seasonal variation of the gravity wave propagation direction at Shigaraki is shown in Fig. 3d. During the Northern Hemisphere's spring (March-April) and summer (MayAugust), the gravity waves preferentially propagated east- ward and northeastward, respectively. During the autumn (September-October), the propagation direction is much more evenly distributed, while in the winter (NovemberFebruary) the waves propagate mainly to the west, between the southwest and northwest. Not many waves are observed during the autumn, which is also noticed from the other observation sites. 
Table 1. Final position of the back traced gravity waves.

\begin{tabular}{llllll}
\hline Final position & Troposphere & $\begin{array}{l}\text { Mesosphere } \\
m^{2}<0\end{array}$ & $\begin{array}{l}\text { Mesosphere } \\
|m| \rightarrow \infty\end{array}$ & Out of range & Total \\
\hline \multirow{2}{*}{ Cachoeira Paulista CP $\left(23^{\circ} \mathrm{S}\right)$} & $\begin{array}{l}24.5 \% \\
35\end{array}$ & $\begin{array}{l}52.4 \% \\
75\end{array}$ & $\begin{array}{l}20.3 \% \\
29\end{array}$ & $\begin{array}{l}2.8 \% \\
4\end{array}$ & $\begin{array}{l}100.0 \% \\
143\end{array}$ \\
\hline \multirow{2}{*}{ Cariri $\left(7^{\circ} \mathrm{S}\right)$} & $24.0 \%$ & $70.0 \%$ & $6.0 \%$ & - & $100.0 \%$ \\
& 78 & 228 & 20 & - & 326 \\
\hline \multirow{2}{*}{ Tanjungsari TJS $\left(7^{\circ} \mathrm{S}\right)$} & $60.0 \%$ & $40.0 \%$ & - & - & 74 \\
\hline \multirow{2}{*}{ Shigaraki $\left(35^{\circ} \mathrm{N}\right)$} & 44 & 30 & - & - & $100.0 \%$ \\
& $43.0 \%$ & $51.2 \%$ & $5.8 \%$ & 31 & - \\
\hline
\end{tabular}

Anisotropy in the wave propagation direction is observed at $\mathrm{CP}$, showing a southeastward direction in summer and a westward direction in winter. On the other side at Shigaraki the propagation is northeastward and southwestward/northwestward in summer and winter, respectively. So, in these mid-low latitudes poleward and eastward directions are more prevailing in summer, and equatorward and westward directions are more significant in winter. However, no large seasonal variability in the propagation direction is observed at TJS and Cariri, where a majority of the waves propagate southward and eastward, respectively.

\subsection{Reverse ray tracing results}

A reversal ray tracing technique was applied for more than 1000 observed gravity waves in order to find out the back trajectory of the waves and to estimate the source locations. The ray tracing results are divided into three groups according to the gravity wave ray path's final position in the atmosphere as follows: 1) waves traced down to the troposphere; 2) waves with the ray path stopped in the mesosphere because of $m^{2}<0$ and 3) waves with the ray path stopped in the mesosphere due to critical level interaction $(|m| \rightarrow \infty)$. The results are summarized in Table 1 , where the number and percentages of the observed waves are also indicated.

The results showed that at $\mathrm{CP}$, Cariri and Shigaraki a majority of the gravity waves' final positions are stopped in the mesosphere, owing to the condition of $m^{2}<0$, while at TJS most of them are traced down into the troposphere. At $\mathrm{CP}$ and Cariri around $24 \%$ of the wave sources are located in the troposphere, at Shigaraki it is around $43 \%$, and at TJS it is $60 \%$. The waves with the ray path stopped in the mesosphere, due to a critical level interaction, are around $20 \%$ at $\mathrm{CP}$ and less than 6\% at Cariri and Shigaraki. At CP, for less than $3 \%$ of the waves, the ray paths left the grid, which are \pm 15 degrees in latitude and longitude around the observation site.

\subsubsection{Gravity waves ray traced down into the troposphere}

Figure 4 presents the final position of the gravity wave ray traced from the mesosphere, around $87 \mathrm{~km}$ altitude, down to the troposphere. In the troposphere the final positions are distributed in an altitude range from the ground to $20 \mathrm{~km}$. Each square in the figure represents the final position of a ray traced gravity wave. The colors represent the waves observed in spring (green), summer (black), autumn (blue) and winter (red), for both Southern and Northern Hemispheres. In order to compare the results between the four stations, the mesh interval in each panel is aligned to $2 \times 2$ degrees in the latitude and longitude directions.

At CP, Fig. 4a, the majority of the ray tracing final positions is located in the west of the observatory, distributed between the southwest and north within an area of $250 \mathrm{~km}$ of radius. Some of them, however, are located $1000 \mathrm{~km}$ away from the observation site. The wave sources are distributed over the continent, and a few of them can be seen over the ocean in the southeast side of CP. At Shigaraki, Fig. 4b, it is clear to see that almost all waves have their origin southwest of the observation site, most of them over the continent. For Cariri, Fig. 4c, the gravity wave sources are distributed all around the observation site, except in the east side (over Atlantic Ocean). At TJS, Fig. 4d, the gravity wave sources are also distributed around the observatory with a preferential location in the north side. Notice that many waves with a tropospheric source are observed during spring and winter. For all stations most of the gravity waves' final positions are located at a distance less than $250 \mathrm{~km}$ away from observation site.

4.2.2 Gravity wave ray path stopped in the mesosphere due to $m^{2}<0$

In the same manner, Fig. 5 shows the final position of the gravity wave with their back trajectories stopped in the mesosphere, due to the condition of the vertical wave number of 


\section{Gravity Waves Ray Path Traced down into the Troposphere}
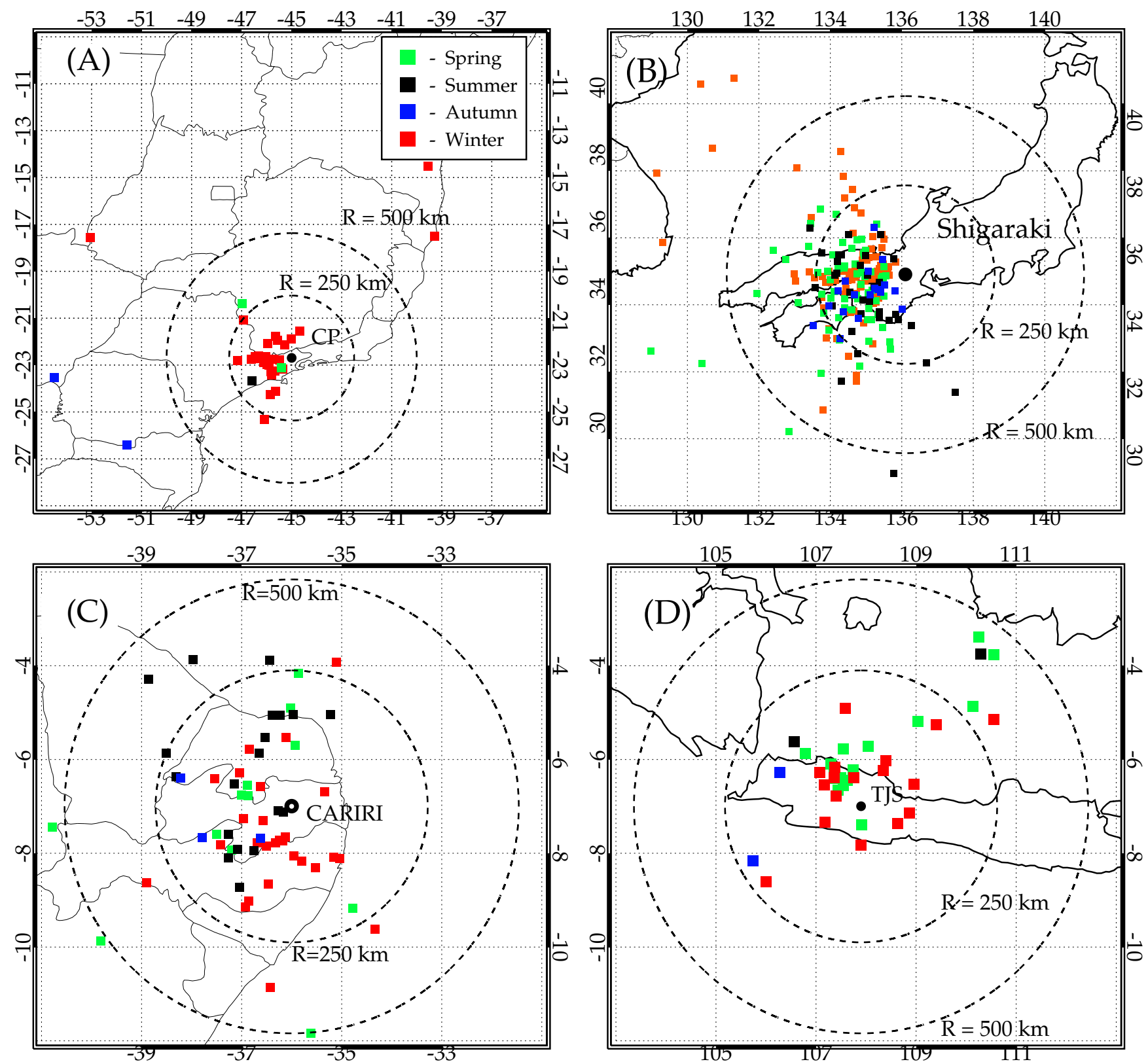

Fig. 4. Tropospheric final positions for the back traced ray path observed at (A) Cachoeira Paulista, (B) Shigaraki (C) Cariri and (D) Tanjungsari. The squares represent the waves observed in spring (green), summer (black), autumn (blue) and winter (red) in the Southern and Northern Hemispheres. As a reference for the final positions two dashed circles with radii of 250 and $500 \mathrm{~km}$ are also plotted.

$m^{2}<0$. The final positions are distributed in an altitude range between 50 and $87 \mathrm{~km}$. The figure scales are the same as in Fig. 4.

For all observatories the final positions of the ray path are located horizontally very close to the observation site. The stop condition due to $m^{2}<0$ is observed in $52 \%$ of the cases at CP, Fig. 5a, and most of them occurred during the summer time. This means that the ray tracing path reached a region where the vertical propagation velocity diminished and was back-reflected to an upward propagation direction. At Shigaraki, Fig. 5b, this stop condition represents $51 \%$ of the observed waves, but in summer, more than $57 \%$ of the waves have their final position in the mesosphere. Figure $5 \mathrm{c}$ shows the ray tracing results at Cariri, where $70 \%$ of the ray tracing stopped in the mesosphere due to $m^{2}<0$. In summer it increased to around $79 \%$. At TJS, Fig. 5 d, $40 \%$ of the gravity wave ray paths stopped in the mesosphere due to $m^{2}<0$. 
Gravity Waves Ray Path Stopped in the Mesosphere due to $\left(m^{2}<0\right)$
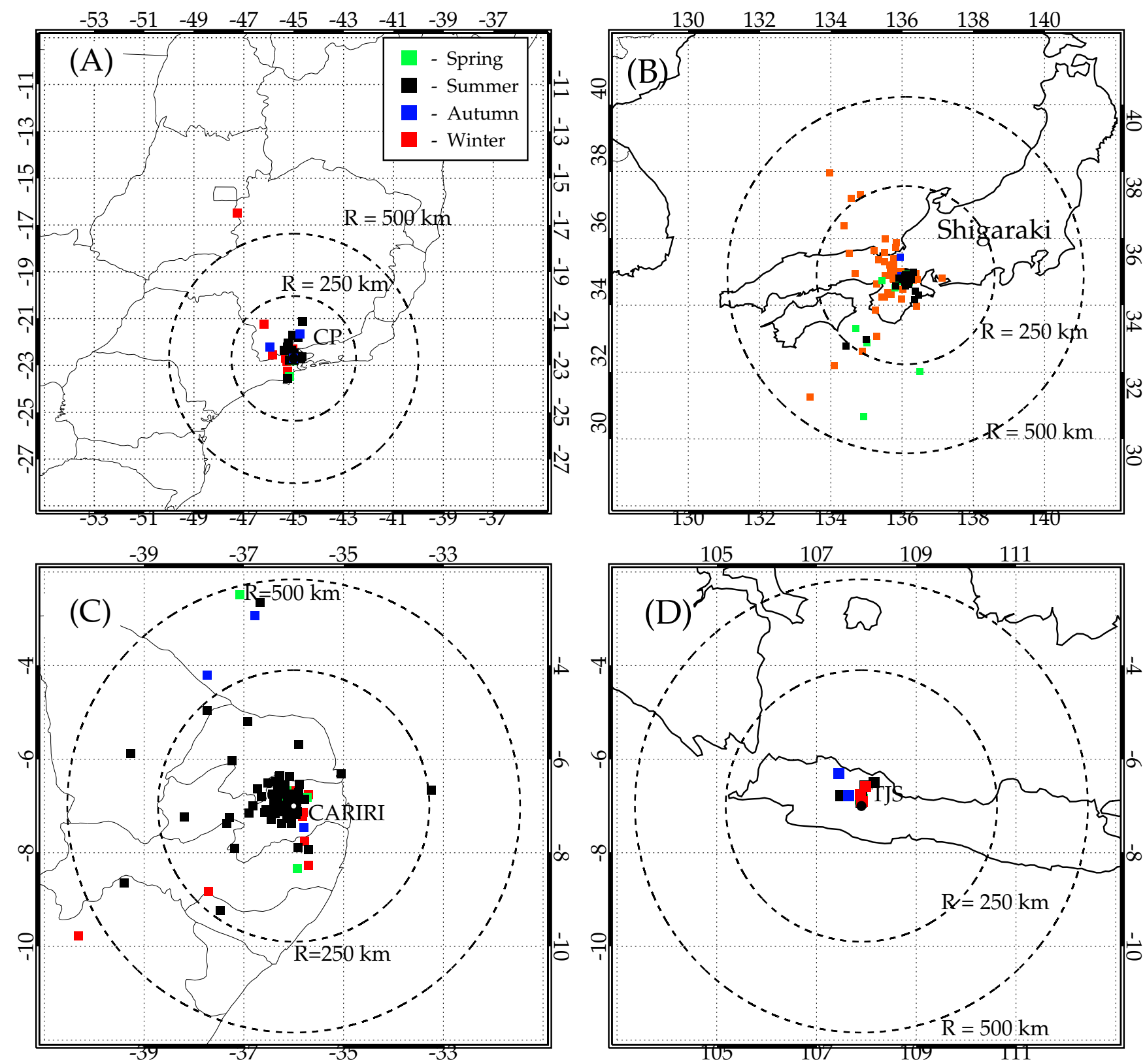

Fig. 5. Same as Fig. 4, but for the back traced ray path stopped in the mesosphere due to $m^{2}<0$.

\subsubsection{Gravity waves ray path stopped in the mesosphere due to a critical level interaction $(|m| \rightarrow \infty)$}

The final positions of the ray tracing path approaching a critical level are presented in Fig. 6. The figure scales are the same as Fig. 4. Most of the final positions of the ray path are located far away form the observation sites. Contrary to the waves with the ray path stopped with $m^{2}<0$, the waves with critical level interactions did not show any seasonal dependency. At CP, Fig. 6a, around $20 \%$ of the waves approached a critical level, while at Shigaraki and Cariri, Figs. 6b and c, less than $6 \%$ of the observed waves showed the feature. At TJS not any wave stopped because this condition was detected.

The gravity wave ray paths which stopped in the mesosphere with $m^{2}<0$ are located closer to the altitude region where they are observed. However, the same does not occur for the waves approaching a critical level. For the latter case the final positions are more spread out around the observations sites, indicating that the waves were propagated with 
Gravity Waves Ray Path Stopped in the Mesosphere due to $(|m| \rightarrow \infty)$
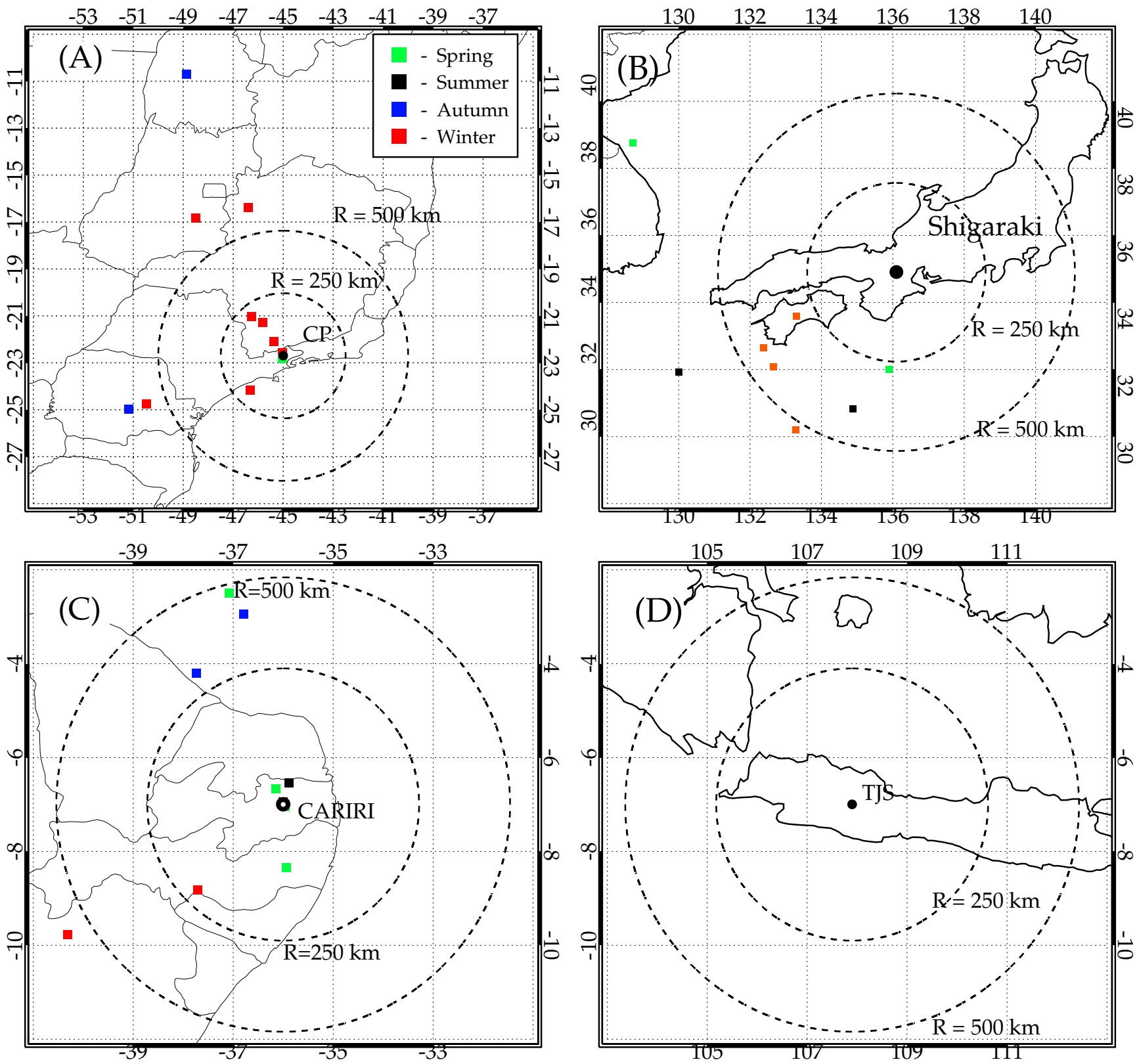

Fig. 6. Same as Fig. 4, but for the back traced ray path stopped in the mesosphere due to a critical level interaction $(|m| \rightarrow \infty)$.

a long distance before their ray paths were stopped. This is understood by the fact that near the critical level, intrinsic wave frequencies and vertical group velocities become small and hence the horizontal motion of the wave packet becomes larger, leaving the waves to propagate for a long distance.
4.3 Gravity waves parameters with different propagation characteristics

Table 2 summarizes all gravity wave characteristics according to the ray path's final position. For comparison the main characteristics of the observed gravity waves are also presented. It is noted that at CP and Cariri more than $70 \%$ of the gravity wave ray traced paths stopped in the mesosphere, while at TJS and Shigaraki this occurrence is low. All the waves with the ray path stopped in the mesosphere with 
Table 2. Gravity waves characteristics according to the ray path final position.

\begin{tabular}{|c|c|c|c|c|c|c|c|c|c|c|c|c|}
\hline \multirow{2}{*}{$\begin{array}{l}\text { GW final position } \\
\text { Parameters }\end{array}$} & \multicolumn{3}{|c|}{ Troposphere } & \multicolumn{3}{|c|}{ Mesosphere $m^{2}<0$} & \multicolumn{3}{|c|}{ Mesosphere $|m| \rightarrow \infty$} & \multicolumn{3}{|c|}{ Observed } \\
\hline & $\lambda_{h}$ & $\tau$ & $c$ & $\lambda_{h}$ & $\tau$ & $c$ & $\lambda_{h}$ & $\tau$ & $c$ & $\lambda_{h}$ & $\tau$ & $c$ \\
\hline $\begin{array}{l}\text { Cachoeira Paulista } \\
\mathrm{CP}\left(23^{\circ} \mathrm{S}\right)\end{array}$ & $15-30$ & $5-15$ & $15-40$ & $10-15$ & $5-10$ & $10-30$ & $10-20$ & $10-20$ & $10-20$ & $5-30$ & $5-15$ & $10-30$ \\
\hline Cariri $\left(7^{\circ} \mathrm{S}\right)$ & $15-35$ & $5-15$ & $15-55$ & $10-20$ & $5-10$ & $10-45$ & $10-20$ & $5-15$ & $5-15$ & $5-25$ & $5-10$ & $10-55$ \\
\hline $\begin{array}{l}\text { Tanjungsari } \\
\text { TJS }\left(7^{\circ} \mathrm{S}\right)\end{array}$ & $15-30$ & $5-10$ & $30-75$ & $15-25$ & $5-10$ & $30-70$ & - & - & - & $5-30$ & $5-10$ & $30-75$ \\
\hline $\begin{array}{l}\text { Shigaraki } \\
\left(35^{\circ} \mathrm{N}\right)\end{array}$ & $20-45$ & $5-20$ & $20-70$ & $5-30$ & $5-15$ & $10-35$ & $10-20$ & $5-20$ & $10-40$ & $5-40$ & $5-15$ & $10-70$ \\
\hline
\end{tabular}

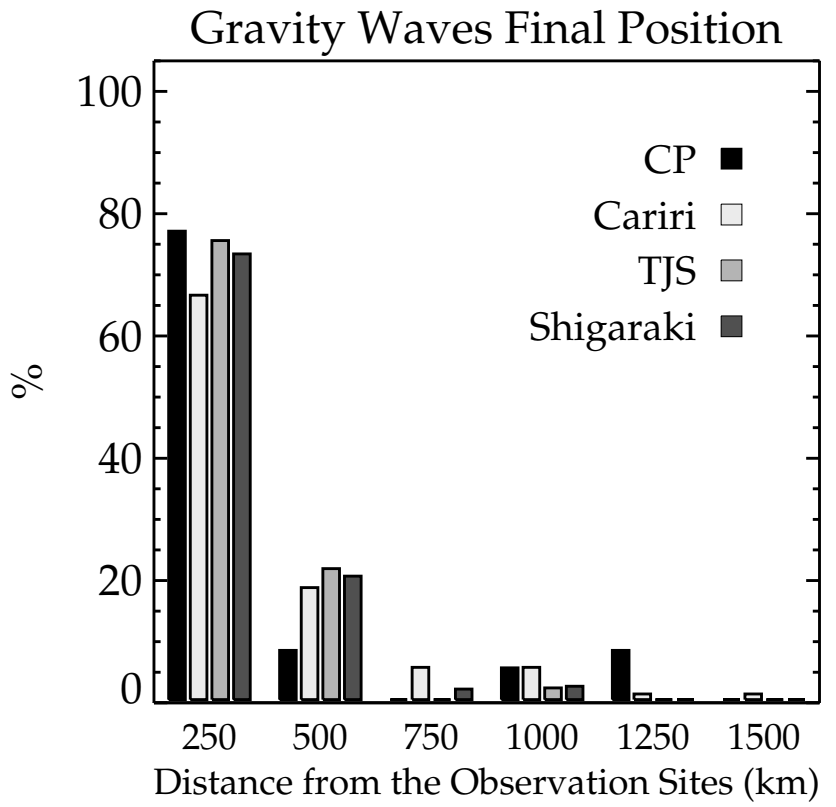

Fig. 7. Histogram showing the distance for the tropospheric sources of gravity waves observed in all stations.

$m^{2}<0$ presented the lowest observed periods with the horizontal wavelength between 10 and $20 \mathrm{~km}$. The waves traced down into the troposphere showed larger horizontal wavelength and phase speed. Among them, the waves observed at Shigaraki and TJS have the largest horizontal wavelength and phase speed.

\section{Discussions}

Our results showed that the observed gravity waves have a larger horizontal phase speed at Cariri $(10-55 \mathrm{~m} / \mathrm{s})$ than at CP $(15-40 \mathrm{~m} / \mathrm{s})$. Similar to it, at TJS the waves are also faster $(30-70 \mathrm{~m} / \mathrm{s})$ than at Shigaraki $(10-70 \mathrm{~m} / \mathrm{s})$. It suggests that there is a large horizontal phase speed at low latitude as pointed out by Nakamura et al. (2003). At Cariri, CP and Shigaraki the majority of the gravity wave ray paths are stopped in the mesosphere due to $m^{2}<0$, which supports a scenario of horizontal propagation of the gravity waves, by reflection and ducting in the mesosphere (Walterscheid et al., 1999; Isler et al., 1997). For these waves, the wave sources could be located more than $1000 \mathrm{~km}$ away from the observed sites. It is notable that in summer most of the back traced gravity waves have their ray path final position stopped in the mesosphere due to $m^{2}<0$ which suggests the presence of ducting waves as proposed by Hecht et al. (2001). On the other hand, at TJS most of the waves were traced back into the troposphere. The difference compared to the other observation sites could be due to a much stronger convective activity near Indonesia, causing the active wave generation near the observational site.

For all the four stations the gravity waves traced back into the troposphere showed larger horizontal wavelengths and phase speeds than the ray paths stopped in the mesosphere. The source regions for those waves in the majority are located in an area less than $250 \mathrm{~km}$ away from the observatory, as presented in Fig. 7. However, some wave sources are located more than $1000 \mathrm{~km}$ from the observation site, like at $\mathrm{CP}$ and Cariri. The traveling time between the troposphere to mesosphere was around or less than $3 \mathrm{~h}$ at $\mathrm{CP}$ and around $2 \mathrm{~h}$ for the others stations.

At CP and Cariri about $24 \%$ of the observed gravity waves originated in the troposphere. Wrasse et al. (2004) showed that the wave sources at $\mathrm{CP}$ are related to the meteorological front activities coming from the southwest mainly in winter and the tropospheric convection during summer. On the other hand, at Cariri, the identified wave source regions are placed in the west and northwest side of the observatory, where deep tropospheric convection frequently occurs (Wrasse et al., 2004). At TJS, the majority of the ray tracing indicates that the gravity wave sources are located in the troposphere. This should correspond to convective cloud activities in the north and northwest side of TJS, as reported by Nakamura et al. (2003). At Shigaraki, about $43 \%$ of ray traced gravity waves showed their origin in the troposphere. The source regions for those waves are located westward 
from the observation site and are broadly spread between the southwest and northwest. The tropospheric jet stream and orography could be responsible for generating the gravity waves.

Although the data sets used for the present study are limited, we could find interesting similarities and differences in the gravity wave characteristics between the 4 observation sites, and different propagation schemes with different latitudes. At present, the number of airglow imagers in the world is growing, which will make it possible to carry on collaborative data analysis of such imaging data as a world-wide network. Such observation schemes would be very important to clarify the global distribution of gravity waves in the MLT region and to discuss the energy and momentum transport from the troposphere to the mesosphere at a global scale.

\section{Summary}

Mesospheric gravity waves were observed in $\mathrm{OH}$ nightglow emissions at four different stations, Cachoeira Paulista (CP) $\left(22.7^{\circ} \mathrm{S}, 45^{\circ} \mathrm{W}\right)$ and Cariri $\left(7^{\circ} \mathrm{S}, 36^{\circ} \mathrm{W}\right)$ Brazil, Tanjungsari (TJS) $\left(6.9^{\circ} \mathrm{S}, 107.9^{\circ} \mathrm{E}\right)$ Indonesia and Shigaraki $\left(34.9^{\circ} \mathrm{N}\right.$, $\left.136^{\circ} \mathrm{E}\right)$ Japan. The observed gravity wave parameters are used as input data into a reversal ray tracing model calculation, in order to back trace the wave trajectory and to estimate their source locations.

At TJS the majority of the waves are traced down into the troposphere. The tropospheric sources of gravity wave are related to meteorological front activities and cloud convections at CP, whereas at Cariri and TJS cloud convections near the equator are the most probable wave source. Tropospheric jet stream and the orography are thought to be the major responsible sources for the waves observed at Shigaraki. For the waves observed at CP, Cariri and Shigaraki during the summer the inverse ray tracing stopped in the mesosphere with around $60 \%$ of the frequency of occurrence. This is due to the condition of $m^{2}<0$, and suggests the presence of ducting waves and/or waves generated in-situ. Gravity waves observed near the equator showed a shorter period and larger phase velocity compared to those observed at low-middle latitudes. The waves traced down into the troposphere showed the largest horizontal wavelength and phase speed.

Acknowledgements. C. M. Wrasse thanks for the opportunity to carry out part of the present work at Research Institute for Sustainable Humanosphere (RISH), Kyoto University. This work was supported by the Fundação de Amparo à Pesquisa do Estado de São Paulo (Fapesp) under the contract number 05/50482-5 and by Conselho Nacional de Desenvolvimento Cientifico e Tecnologico (CNPq) contract number 150039/2004-2. T. Tsuda and T. Nakamura thank all the staff of Tanjungsari observatory of LAPAN for their efforts of continuous operation of the imager system. This study is supported by Monbusho Grant-in-Aid for Scientific Research (B) 14403008 and Monbusho Grant-in-Aid for Scientific Research on Priority Areas (B) 13136203.
Topical Editor U.-P. Hoppe thanks A. Hauchecorne and another referee for their help in evaluating this paper.

\section{References}

Bertin, F., Testud, J., Kersley, L., and Rees, P. R.: The meteorological jet stream as a source of medium-scale gravity waves in the thermosphere: an experimental study, J. Atmos. Terr. Phys., 40(10-11), 1161-1183, 1978.

Brown, L. B., Gerrard, A. J., Meriwether, J. W., and Makela, J. J.: All-sky imaging observations of mesospheric fronts in OI $557.7 \mathrm{~nm}$ and broadband $\mathrm{OH}$ airglow emissions: Analysis of frontal structure, atmospheric background conditions, and potential sourcing mechanisms, J. Geophys. Res., 109, D19104, doi:10.1029/2003JD004223, 2004.

Eckermann, S. D. and Marks, C. J.: GROGRAT: A new model of the global propagation and dissipation of atmospheric gravity waves, Adv. Space Res., 20(6), 1253-1256, 1997.

Fleming, E. L., Chandra, S., Barnett, J. J., and Corney, M.: Zonal mean temperature, pressure, zonal wind, and geopotential height as functions of latitude, COSPAR International Reference Atmosphere: 1986, Part II: Middle Atmosphere Models, Adv. Space Res., 10(12), 11-59. 1990.

Fritts, D. C. and Alexander, M. J.: Gravity wave dynamics and effects in the middle atmosphere, Rev. Geophys., 41(1), 1003, doi:10.1029/2001RG000106, 2003.

Gerrard, A. J., Kane, T. J., Eckermann, S. D., and Thayer, J. P.: Gravity waves and mesospheric clouds in the summer middle atmosphere: A comparison of lidar measurements and ray modeling of gravity waves over Sondrestrom, Greenland, J. Geophys. Res., 109, D10103, doi:10.1029/2002JD002783, 2004.

Hagan, M. E. and Forbes, J. M.: Migrating and nonmigrating semidiurnal tides in the upper atmosphere excited by tropospheric latent heat release, J. Geophys. Res., 10(A2), 1062, doi:10.1029/2002JA009466, 2003.

Hecht, J. H., Walterscheid, R. L., and Ross, M. N.: First measurements of the two-dimensional horizontal wave number spectrum from CCD images of the nightglow, J. Geophys. Res., 99(A6), 11449-11 460, 1994.

Hecht J. H., Walterscheid, R. L., Hickey, M. P., and Franke, S. J.: Climatology and modeling of quasi-monochromatic atmospheric gravity waves observed over Urbana Illinois, J. Geophys. Res., 106(D6), 5181-5191, 2001.

Hertzog, A., Souprayen, C., and Hauchecorne, A.: Observation and backward trajectory of an inertio-gravity wave in the lower stratosphere, Ann. Geophys., 19(9), 1141-1155, 2001.

Isler, J. R., Taylor, M. J., and Fritts, D. C.: Observational evidence of wave ducting and evanescence in the mesosphere, J. Geophys. Res., 102(D22), 26301-26313, 1997.

Jones, W. L.: Ray tracing for internal gravity waves, J. Geophys. Res., 74(8), 2028-2033, 1969.

Lighthill, J.: Waves in fluids. London: Cambridge University Press, v.1, 1978.

Marks, C. J. and Eckermann, S. D.: A three-dimensional nonhydrostatic ray-tracing model for gravity waves: formulation and preliminary results for the middle atmosphere, J. Atmos. Sci., 52(11), 1959-1984, 1995.

Medeiros, A. F., Taylor, M. J., Takahashi, H., Batista, P. P., and Gobbi, D.: An unusual airglow wave event observed at Ca- 
choeira Paulista 23 degrees S, Adv. Space Res., 27(10), 17491754, 2001.

Medeiros, A. F., Buriti, R. A., Machado, E. A., Takahashi, H., Batista, P. P., Gobbi, D., and Taylor, M. J.: Comparison of gravity wave activity observed by airglow imaging at two different latitudes in Brazil, J. Atmos. Sol-Terr. Phys., 66(6-9), 647-654, 2004.

Nakamura, T., Higashikawa, A., Tsuda, T., and Matsushita, Y. T.: Seasonal variations of gravity wave structures in $\mathrm{OH}$ airglow with a CCD imager at Shigaraki, Earth Planets Space, 51(7-8), 897-906, 1999.

Nakamura, T., Aono, T., Tsuda, T., Admiranto, A. G., Achmad, E., and Suranto.: Mesospheric gravity waves over a tropical convective region observed by $\mathrm{OH}$ airglow imaging in Indonesia, Geophys. Res. Lett., 30(17), 1882-1885, 2003.

Schubert, G. and Waterscheid, R. L.: Wave-driven fluctuations in $\mathrm{OH}$ nightglow from an extended source region, J. Geophys. Res., 93, 9903-9915, 1988.

Swenson, G. R. and Mende, S. B.: OH emission and gravity waves (including a breaking waves) in all-sky imagery from Bear Lake, UT, Geophys. Res. Lett., 21, 2239-2242, 1994.

Swenson, G. R. and Gardner, C. S.: Analytical models for the responses of the mesospheric $\mathrm{OH}^{*}$ and Na layers to atmospheric gravity waves, J. Geophys. Res., 103, 6271-6294, 1998.

Swenson, G. R., Haque, R., Yang, W., and Gardner, C. S.: Momentum and energy fluxes of monochromatic gravity waves observed by an $\mathrm{OH}$ imager at Starfire Optical Range, New Mexico, J. Geophys. Res., 104(D6), 6067-6080, 1999.

Tarasick, D. W. and Hines, C. O.: The observable effects of gravity waves on airglow emissions, Planet. Space Sci., 38(9), 11051119, 1990.
Taylor, M. J., Bishop, M. B., and Taylor, V.: All-sky measurements of short period waves imaged in the OI $(557.7 \mathrm{~nm}), \mathrm{Na}$ $(589.2 \mathrm{~nm})$ and near infrared $\mathrm{OH}$ and $\mathrm{O} 2(0,1)$ nightglow emissions during the ALOHA-93 campaign, Geophys. Res. Lett., 22(20), 2833-2836, 1995.

Taylor, M. J., Pendleton, W. R. J., Clark, S., Takahashi, H., Gobbi, D., and Goldberg, R. A.: Image measurements of short-period gravity waves at equatorial latitudes, J. Geophys. Res., 102(D22), 26 283-26 299, 1997.

Walterscheid, R. L., Hecht, J. H., Vincent, R. A., Reid, I. M., Woithe, J., and Hickey, M. P.: Analysis and interpretation of airglow and radar observations of quasi-monochromatic gravity waves in the upper mesosphere and lower thermosphere over Adelaide, Australia, J. Atmos. Sol.-Terr. Phys., 61(6), 461-478, 1999.

Wrasse, C. M., Nakamura, T., Tsuda, T., Takahashi, H., Gobbi, D., Medeiros, A. F., and Taylor, M. J.: Atmospheric wind effects on the gravity wave propagation observed at 22.7 degrees $\mathrm{S}-$ Brazil, Adv. Space Res., 32(5), 819-824, 2003.

Wrasse, C. M., Takahashi, H., Nakamura, T., Gobbi, D., Taylor, M. J., and Medeiros, A. F.: Searching for gravity wave sources in the equatorial and low-middle latitude regions over Brazil, in: 35th COSPAR Scientific Assembly, 2004, Paris, 35th COSPAR Scientific Assembly, p. 3548, 2004.

Wrasse, C. M., Nakamura, T., Tsuda, T., Takahashi, H., Medeiros, A. F., Taylor, M. J., Gobbi, D., Salatun, A., Suratno, Achmad, E., and Admiranto, A. G.: Reverse ray tracing of the mesospheric gravity waves observed at $23^{\circ} \mathrm{S}$ (Brazil) and $7^{\circ} \mathrm{S}$ (Indonesia) in airglow imagers, J. Atmos. Sol-Terr. Phys., 68(2), 163-181, 2006. 